\title{
ANTIOXIDANT, ANTIBACTERIAL POTENTIAL AND HPLC ANALYSIS OF Dioscorea alata BULB
}

\author{
Md. Anisuzzman' ${ }^{1}$, Md. Nazmul Hasan Zilani ${ }^{1 *}$, Sharmin Sultana Khushi ${ }^{2}$, Md. \\ Asaduzzman ${ }^{3}$, Md. Golam Hossain ${ }^{1}$
}

1Pharmacy Discipline, Life Science School

Khulna University, Khulna9208, Bangladesh

${ }^{2}$ Fisheries and Marine

Resource Technology

Discipline, Khulna

University, Khulna, 9208,

Bangladesh

${ }^{3}$ Department of Fisheries,

Sylhet Agricultural

University, Sylhet, 3100

Bangladesh

Submitted: $10-11-2015$

Revised: $17-12-2015$

Accepted: 08-01-2016

*Corresponding author Md. Nazmul Hasan Zilani

Email:

mnhzilani09@gmail.com

\section{INTRODUCTION}

Therapeutic uses of plants had in effect stored at the very beginning of human life on earth. The World Health Organization estimated that $80 \%$ of the populations of developing countries rely on traditional medicine. Also modern pharmacopoeia still contains at least $25 \%$ drugs derived from plants (Ghani, 2003). Dioscorea alata L. (Dioscoreaceae) locally known as mate alu is tuberous root vegetable. It is native to tropical regions throughout the world. It is well known for its high nutritional content (Osagie 1992). $D$. alata is a cheaper source of carbohydrate that contains more than $85 \%$ of the carbohydrate (Kochhar 1981), minerals of calcium, phosphorus, iron and vitamins such as riboflavin, thiamin etc. (Coursey 1967). Previous studies reported the presence of cyanidin 3,5-diglucoside; cyanidin3-glucoside; cyanidin-3-rhamnoglucoside; (Lula et al., 2015) hydro-Q chromene; gamma-tocopherol-9; RRR-alpha-tocopherol; coenzyme Q; 1-feruloylglycerol; (Cheng et al.,
2007) 4-Phenylbutan-2-one; (Gramshaw and Osinowo, 1982) alanins, cyaniding, peonidin (Moriya et al., 2015) in D alata. In Bangladesh traditionally it is used against leprosy and tumor. The present study was designed to evaluate antioxidant, antibacterial potential of methanol extract of $D$. alata. HPLC analysis was done to identify the existence of naturally occurring bioactive polyphenols.

\section{MATERIAL AND METHODS Chemicals and reagents}

Arbutin, gallic acid, hydroquinone, (+)catechin hydrate, vanillic acid, caffeic acid, Syringic acid, (-)-epicatechin, vanillin, $p$ coumaric acid, trans-ferulic acid, rutin hydrate, ellagic acid, benzoic acid, rosmarinic acid, myricetin, quercetin, trans-cinnamic acid, kaempferol, 2, 2-Diphenyl-1-picrylhydrazyl, and butylated hydroxyl toluene were purchased from Sigma-Aldrich (St. Louis, MO, USA). Acetonitrile (HPLC), methanol (HPLC), acetic acid (HPLC), and ethanol was obtained from Merck (Darmstadt, Germany). 


\section{Microorganisms}

Twelve pathogenic bacterial strains (Six gram positive and six gram negative) were collected from Microbiology Laboratory of Pharmacy Discipline, Khulna University, Bangladesh.

\section{Preparation of crude extract}

Dioscorea alata bulb was collected from Khulna, Bangladesh and identified by the experts of Bangladesh National Herbarium, Dhaka (Accession no. DACB-37524). Cold extraction process in methanol was used get the extract. The crude extract was stored in a refrigerator at $4^{\circ} \mathrm{C}$ until experiment to commence.

\section{Phytochemical test}

Different standard qualitative chemical test were carried out to identify different phytochemical constituents such as carbohydrates, alkaloids, glycosides, phenolic compounds, flavonoids, tannins, steroids, gum, saponins and acidic compounds (Ghani, 2005).

\section{DPPH free radical scavenging assay}

Free radical scavenging activity was quantitatively estimated using DPPH (Islam et al., 2014). From the stock solution of $1024 \mu \mathrm{g} / \mathrm{mL}$ of extract, serial dilution was carried out to obtain the desired concentration series $(512,256,128,64,32,16,8,4,2$, $1 \mu \mathrm{g} / \mathrm{mL})$. In $1 \mathrm{~mL}$ diluted extract solution from each concentration, $3 \mathrm{~mL}$ of immediately prepared 0.004\% w/v DPPH solution was added. After incubation for $30 \mathrm{~min}$ in dark at room temperature, the presence of $\mathrm{DPPH}$ in each concentration of the sample was detected at $517 \mathrm{~nm}$. Ascorbic acid was used as standard. The antiradical activity of the extract and standard was calculated using the formula: \% discoloration $=\left[\left(\mathrm{Abs}_{0}-\mathrm{Abs}_{1}\right) / \mathrm{Abs}_{0}\right] \times 100$; where $\mathrm{Abs}_{0}$ is the absorbance of control and $\mathrm{Abs}_{1}$ is the absorbance of extract or standard. Concentration of extract providing 50\% discoloration of DPPH solution ( $\mathrm{IC}_{50}$ value), was estimated from the graph obtained by plotting the percent discoloration against concentration.

\section{Reducing power assay}

The reducing power of extract was determined by the method of Oyaizu (Saha et al., 2013) with modifications. $2.5 \mathrm{~mL}$ phosphate buffer $(0.2 \mathrm{~mol} / \mathrm{L} ; \mathrm{pH} 6.6)$ and $2.5 \mathrm{~mL}$ of $1 \%$ $\mathrm{w} / \mathrm{v}$ potassium ferric cyanide were subsequently added to $1 \mathrm{~mL}$ of various concentrations of extract solution. It was incubated for $20 \mathrm{~min}$ at $50^{\circ} \mathrm{C}$ and then cooling at room temperature and $2.5 \mathrm{~mL}$ of $10 \% \mathrm{w} / \mathrm{v}$ thiochloroacetic acid was added to it. The mixture was centrifuged at $3000 \mathrm{rpm}$ for $10 \mathrm{~min}$. $2.5 \mathrm{~mL}$ aliquot of supernatant was mixed with $2.5 \mathrm{~mL}$ distilled water and $0.50 \mathrm{~mL}$ of $0.1 \% \mathrm{w} / \mathrm{v}$ ferric chloride with continuous shaking. Ten minutes later the absorbance was measured at $700 \mathrm{~nm}$ against blank. Butylated hydroxy toluene (BHT) was used to compare the reducing power of the extract.

\section{Total phenol content}

The total phenol content of the extract was determined by the modified FolinCiocalteu method (Hemayet et al., 2013). Extract $(1 \mathrm{mg} / \mathrm{mL})$ was mixed with $5 \mathrm{~mL}$ of diluted Folin-Ciocalteu reagent. Then $4 \mathrm{~mL}$ sodium carbonate $(7.5 \% \mathrm{w} / \mathrm{v})$ was added to the mixture and allowed to incubate at $40^{\circ} \mathrm{C}$ for $30 \mathrm{~min}$. Absorbance was measured at $765 \mathrm{~nm}$. The standard calibration curve was prepared using gallic acid $(0-1 \mathrm{mg} / \mathrm{mL})$. Based on the absorbance of the extract, total phenol content was calculated and expressed in terms of $\mathrm{mg}$ of gallic acid equivalent per gram of dry extract.

\section{Total flavonoid Content}

Aluminum chloride colorimetric method was used to determine the total flavonoid content in the extract (Shah et al., 2012). Four milliliters distilled water and $0.3 \mathrm{~mL}$ $5 \% \mathrm{w} / \mathrm{v}$ sodium nitrate was subsequently mixed into $1 \mathrm{mg} / \mathrm{mL}$ extract. Five minutes later, $0.3 \mathrm{~mL} 10 \% \mathrm{w} / \mathrm{v}$ aluminum chloride was added. At the sixth minute $2 \mathrm{~mL}$ of $1 \mathrm{M}$ sodium hydroxide was added and the volume was adjusted to $10 \mathrm{~mL}$ with distilled water. Absorbance was measured at $510 \mathrm{~nm}$ against blank. Quercetin was used for standard calibration curve. After reading the quercetin equivalent from the calibration line, total content of flavonoid was expressed as $\mathrm{mg}$ quercetin equivalent (QE) per gram of dry plant extract. 


\section{HPLC detection and quantification of polyphenolic compounds}

Detection and quantification of selected phenolic compounds in the methanol extract were determined by HPLC-DAD analysis Ismet et al. (2014). It was carried out on a Dionex UltiMate 3000 system equipped with quaternary rapid separation pump (LPG3400RS) and photodiode array detector (DAD3000RS). Separation was performed using $\mathrm{C}_{18}$ $(5 \mu \mathrm{m})$ Dionex column $(4.6 \times 250 \mathrm{~mm})$ at $30^{\circ} \mathrm{C}$ with a flow rate of $1 \mathrm{~mL} / \mathrm{min}$ and an injection volume of $20 \mu \mathrm{l}$. The mobile phase consisted of solvent $\mathrm{A}$, solvent $\mathrm{B}$ and solvent $\mathrm{C}$ with the gradient elution program of $5 \% \mathrm{~A} / 95 \% \mathrm{~B}(0-$ $5 \mathrm{~min}), 10 \% \mathrm{~A} / 90 \% \mathrm{~B}(6-9 \mathrm{~min}), 15 \% \mathrm{~A} / 75 \% \mathrm{~B}$ $/ 10 \% \mathrm{C}$ (11-15min), $20 \% \mathrm{~A} / 65 \% \mathrm{~B} / 15 \% \mathrm{C}$ (16$19 \mathrm{~min}$ ), $30 \% \mathrm{~A} / 50 \% \mathrm{~B} / 20 \% \mathrm{C}$ (20-29min), $40 \%$ $\mathrm{A} / 30 \% \mathrm{~B} / 30 \% \mathrm{C}(30-35 \mathrm{~min})$ and $100 \% \mathrm{~A}(36-$ 40in). In where solvent $A$ is acetonitrile, solvent B is ace tic acid solution ( $\mathrm{pH}$ 3.0) and solvent $\mathrm{C}$ is methanol. The UV detector was set to 280 $\mathrm{nm}$ (0-22.0min), changed to $320 \mathrm{~nm}$ (23$28.0 \mathrm{~min}$, again change to $280 \mathrm{~nm}(29-35 \mathrm{~min})$ and finally to $380 \mathrm{~nm}$ (36-40min) and held for the rest of the analysis period while the diode array detector was set at an acquisition range from 200 to $700 \mathrm{~nm}$. For the preparation of calibration curve, a standard stock solution was prepared in methanol containing arbutin, (-)epicatechin $(5 \mu \mathrm{g} / \mathrm{mL}$ each), gallic acid, hydroquinone, vanillic acid, rosmarinic acid, myricetin $(4 \mu \mathrm{g} / \mathrm{mL}$ each), caffeic acid, Syringic acid, vanillin, trans-ferulic acid $(3 \mu \mathrm{g} / \mathrm{mL}$ each), $p$-coumaric acid, quercetin, kaempferol $(2 \mu \mathrm{g} / \mathrm{mL}$ each), (+)-catechin hydrate, ellagic acid $(10 \mu \mathrm{g} / \mathrm{mL}$ each), trans-cinnamic acid $(1 \mu \mathrm{g} / \mathrm{mL})$, rutin hydrate $(6 \mu \mathrm{g} / \mathrm{mL})$ and benzoic acid $(8 \mu \mathrm{g} / \mathrm{mL})$. A solution of the extract was prepared in methanol having the concentration of $10 \mathrm{mg} / \mathrm{mL}$. Prior to HPLC analysis, all the solutions were filtered through $0.20 \mu \mathrm{m}$ syringe filter (Sartorius, Germany) and then degassed in an ultrasonic bath (Hwashin, Korea) for $15 \mathrm{~min}$.

\section{Antibacterial Activity}

Disk diffusion assay was applied to assess antibacterial activity of extract against both gram-positive and gram-negative bacterial strains. Second subculture of each bacterial strain was prepared. Each subculture was transferred into vials containing nutrient broth and incubated at $37^{\circ} \mathrm{C}$ for $2-4 \mathrm{~h}$. Then seeded nutrient agar medium was poured into petri-dishes and let to solidify at room temperature. Discs impregnated with extract (200, 300 and $500 \mu \mathrm{g} /$ disk), standard antibiotic disc (Kanamycin 30 $\mu \mathrm{g} /$ disk) and blank discs containing ethanol (control) were placed on the petri-dishes and incubated at $37^{\circ} \mathrm{C}$ for $18-24 \mathrm{~h}$ and the zone of inhibition was measured in millimeters (Pervin et al., 2013).

\section{RESULTS AND DISCUSSION}

In traditional societies nutrition and health care are strongly interconnected and many plants have been consumed both as food and for medicinal purposes. In recent years much attention has been devoted to natural antioxidant and their association with health benefits (Arnous et al., 2001). All these activities are due to the phytochemicals present in the plant. Preliminary phytochemical screening of the methanol extract of $D$. alata indicated the presence of carbohydrate, alkaloids, glycosides, phenolic compounds, flavonoids, tannins, steroids and gum but absence of protein and saponin. Phenolic compounds are wide spread constituents of edible and non-edible plants. It has recently showed that phenolic antioxidants in herbs have capacities of quenching lipid peroxidation, preventing DNA oxidative damage and scavenging reactive oxygen species (Ksouri et al., 2009). The antioxidant effect is mainly due to the hydroxyl groups present in their structure (Rice-Evans et al., 1997). Flavonoids are well-known antioxidant constituents of plants and possess a broad spectrum of chemical and biological activity, including radical scavenging and antibacterial properties (Miliauskas et al., 2004). The total phenol content of the extract was found to be $222.99 \mathrm{mg}$ GAE/g of dry extract. Meanwhile the total flavonoid content was $98.95 \mathrm{mg} \quad \mathrm{QE} / \mathrm{g}$ of dried plant extract. Identification and quantification of individual phenolic compounds in the methanol extract of $D$. alata were analysed by HPLC. The chromatographic separations of polyphenols in standard and methanol extract are shown in figure 1 and 2 , respectively. 
Table I. Composition of polymeric matrices for the different formulation

\begin{tabular}{lcccc}
\hline & F1 & F2 & F3 & F4 \\
\hline Timolol maleate $(\mathrm{mg})$ & 60 & 60 & 60 & 60 \\
Guar gum $(\% \mathrm{w} / \mathrm{v})$ & $0.25 \%$ & $0.50 \%$ & $0.75 \%$ & $1.0 \%$ \\
Dibutyl phthalate (w/w of polymer) & $30 \%$ & $30 \%$ & $30 \%$ & $30 \%$ \\
Purified water (mL) & 100 & 100 & 100 & 100 \\
\hline
\end{tabular}

Table II. Evaluation of ocular inserts

\begin{tabular}{ccccc}
\hline Code & Thickness $(\boldsymbol{\mu m})$ & Weight $(\mathbf{m g})$ & Surface $\mathbf{~ H H}$ & \% drug content \\
\hline Batch A & $41.12 \pm 0.04$ & $0.84 \pm 0.07$ & $6.5-7.0$ & $98.69 \pm 0.58$ \\
Batch B & $54.52 \pm 0.03$ & $1.07 \pm 0.04$ & $6.5-7.0$ & $99.66 \pm 0.88$ \\
Batch C & $69.09 \pm 0.05$ & $1.68 \pm 0.10$ & $6.5-7.0$ & $97.92 \pm 0.67$ \\
Batch D & $79.90 \pm 0.03$ & $2.11 \pm 0.09$ & $6.5-7.0$ & $96.37 \pm 0.58$ \\
\hline
\end{tabular}

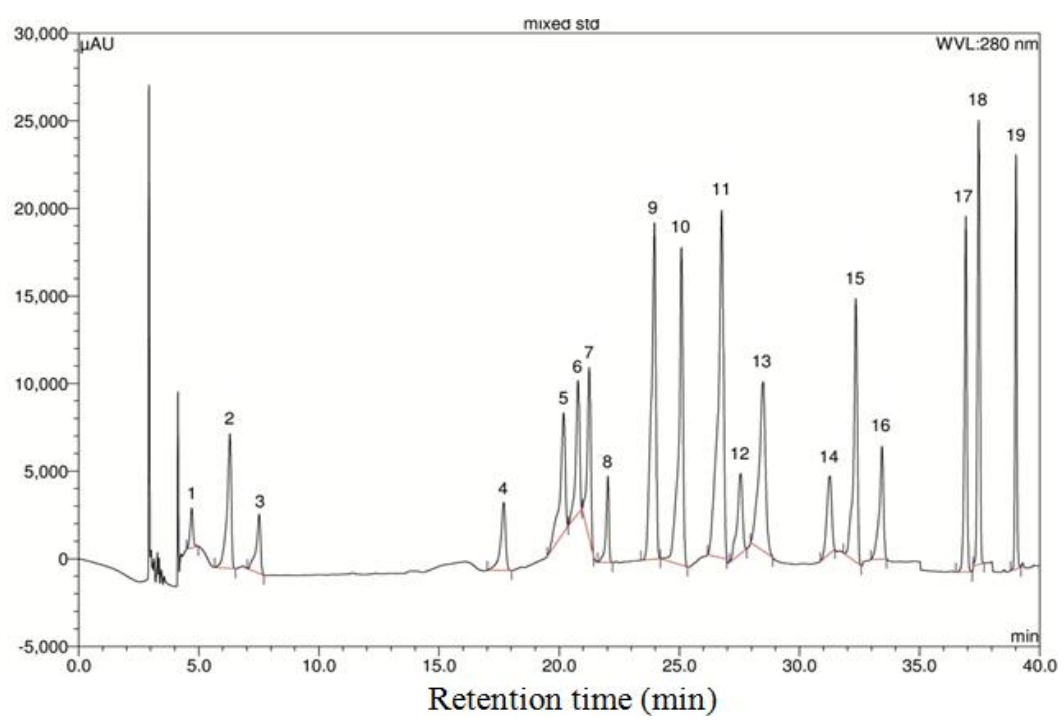

Figure 1: HPLC chromatogram of a standard mixture of polyphenolic compounds. Peaks 1: arbutin, 2: gallic acid, 3: hydroquinone, 4: (+)-catechin, 5: vanillic acid 6: caffeic acid, 7: syringic acid, 8: (-)-epicatechin, 9: vanillin, 10: p-coumaric acid, 11: trans-ferulic acid, 12: rutin hydrate, 13: ellagic acid. 14: benzoic acid, 15: rosmarinic acid, 16: myricetin, 17: quercetin, 18: trans-cinnamic acid, 19: kaempferol.

The content of each phenolic compound was calculated from the corresponding calibration curve and presented as the mean of five determinations as shown in table I. The experimental results indicated presence of myricetin, gallic acid, ellagic acid, vanillic acid, syringic acid, epicatechin, vanillin, p-coumaric acid, trans-cinnamic acid and kaempferol. Among the compounds myricitene, a member of flavonoids possess strong antioxidant. Antioxidant activity of HPLC detected compounds is recognized in previous studies (Emira et al., 2014). The investigated extract showed a free radical scavenging activity in the DPPH assay $\left(\mathrm{IC}_{50}=14.68 \mu \mathrm{g} / \mathrm{mL}\right)$ which is comparable to that of standard antioxidant ascorbic acid $\left(\mathrm{IC}_{50}=24.95 \mu \mathrm{g} / \mathrm{mL}\right)$. Also reducing power of extract was comparable to that of standard. Extract showed maximum absorption of 1.317 and 0.942 in where 


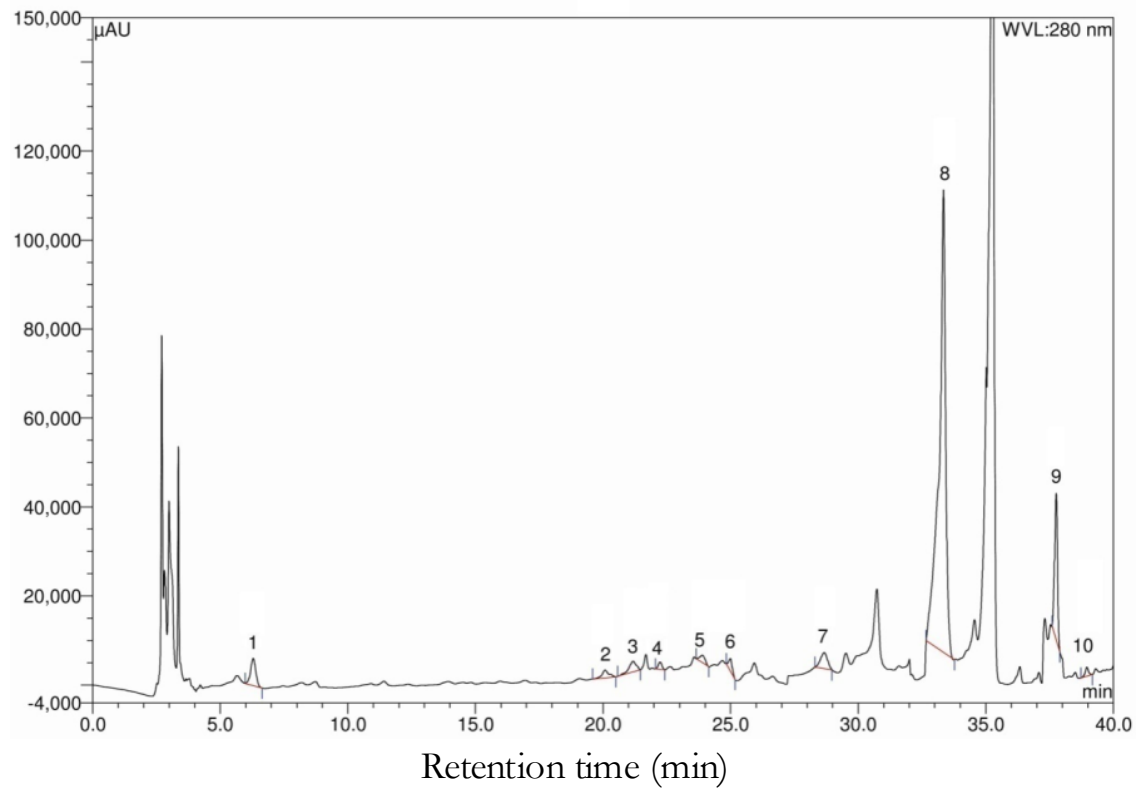

Figure 2: HPLC chromatogram of $D$. alata. Peaks 1: gallic acid, 2: vanillic acid, 3: syringic acid, 4: epicatechin, 5: vanillin, 6: p-coumaric acid, 7: ellagic acid, 8: myricetin, 9: trans-cinnamic acid, 10: kaempferol.

standard BHT showed 1.472 and 1.242 at $1 \mathrm{mg} / \mathrm{mL}$ and $0.5 \mathrm{mg} / \mathrm{mL}$ respectively. Strong DPPH free radical and reducing power activity of the extract may be due to the presence of higher content of myricetin along with other detected polyphenols that change DPPH free radical and Fe (III) in their reduced form.

The extract also showed antibacterial activity against all experimental bacterial strains except Staphylococcus epidermidis. At the concentration of $500 \mu \mathrm{g} / \mathrm{disc}$ extract showed maximum zone of inhibition of $17.16 \mathrm{~mm}$ against Shigella dysenteriae and at lower dose $200 \mu \mathrm{g} /$ disc maximum zone of inhibition was $8.52 \mathrm{~mm}$ against Shigella flexneri (table II). Antibacterial activity of plants can be detected by observing the growth response of various microorganisms to those plant extracts that are placed in contact with them. Medicinal plants containing phenolic and flavonoids have been reported to possess antibacterial activity in previous studies (Emira et al., 2014). Antimicrobial activity of myricetin, gallic acid, vanillic acid, kaempferol, $p$-coumaric acid, transcinnamic acid, epicatechine, vanillin has been reported (Monika et al., 2014; Emira et al., 2014). In the present study antibacterial activity of $D$. alata might be due to the natural polyphenols present in the extract.

\section{CONCLUSION}

Present study showed that methanol extract of $D$. alata exerts antioxidant and antibacterial activities. The presence of myricetin along with other detected polyphenols might contribute to these activities.

\section{ACKNOWLEDGEMENT}

Authors are grateful to the authorities of Pharmacy Discipline, Life Science School, Khulna University, Bangladesh for providing excellent working facilities.

\section{REFE RE NCE}

Arnous A., Makris DP., Kefalas P., 2001. Effect of principal polyphenolic components in relation to antioxidant characteristics of aged red wines. J. Agric. Food. Chem., 49:5736-5742.

Cheng WY., Kuo YH., Huang CJ., 2007. Isolation and identification of novel estrogenic compounds in yam tuber 
(Dioscorea alata Cv. Tainung No. 2). J. Agric. Food. Chem., 55(18):7350-58.

Coursey DG., 1967. Yams: an account of the nature, origins, cultivation, and utilization of the useful members of Dioscoraceae. London: Longmans, Green and Co. Ltd. pp. 56-65

Emira N., Mejdi S., Inès N., Eulogio V., Mahjoub A., Abdulbasit A., 2014. Comparative study on the antifungal and antioxidant properties of natural and colored Juglans regia L. barks: A high activity against vaginal Candida strains. Life. Sci. J., 11(8): 327-35.

Ghani A., 2003. Medicinal Plants of Bangladesh. 2nd edition. Dhaka: Bangladesh, The Asiatic Society of Bangladesh. pp.13-18.

Ghani A., 2005. Practical Phytochemistry. Parash Publishers, Dhaka, Bangladesh. pp 8-20.

Gramshaw JW., Osinowo FAO., 1982. Volatile components of cooked tubers of the water yam (Dioscorea alata). J. Sci. Food. Agri., 33(1): 71-80.

Hemayet H., Ismet AJ., Sariful IH., Jamil AS., Shubhra KD., Arpona H., Arif A.. 2013. Anti-inflammatory and antioxidant activities of ethanolic leaf extract of Brownlowia tersa (L.) Kosterm. Orient. Pharm. Exp. Med., DOI 10.1007/s13596013-0109-3.

Islam MK., Nripendra NB., Sanjib S., Hemayet H., Ismet AJ., Tanzir AK., Khalijah A., Jamil AS., 2014. Antinociceptive and Antioxidant Activity of Zanthoxylum budrunga Wall (Rutaceae) Seeds. Sci.World J., Article ID 869537, 7 pages.

Ismet AJ., Proity NA., Nasima K., Tanzir AK., Mohammad MR., Arpona H., Hemayet H., 2014. Comparative Study of antinociceptive activity and phenolic content of the ethanol extracts of Piper nigrum and Piper longum fruits. Int. J. Pharm. Sci. Rev. Res., 27(1): 47-52.

Kochhar SL., 1981. Tropical crops: A textbook of economy botany. London: Macmillan Pub Ltd. pp.125-132.

Ksouri R., Fallah H., Megdchi W., Trabelsi N., Mhamdi B., Chaieb K., Bakrouf A., Magny C., Abdelly C., 2009. An antioxidant and antimicrobial activity of edible medicinal halophyte Tamarix gallica L. and related polyphenolic constitutes. Food. Chem. Toxicol., 47: 2083-2091.

Lula N., Aman W., Nuri A., Eko HP., Takahiro N., Koji I., 2015. Chemical Characterization of Flour Fractions from Five Yam (Dioscorea alata) Cultivars in Indonesia. J. Eng. Technol. Sci., 47(1): 92103.

Miliauskas G., Venskutonis PR., VanBeek JA., 2004. Screening of free radical scavenging activity of some medicinal and aromatic plants. Food. Chem., 85: 231-237.

Monika M., Nomita G., Palak P., Varsha M., Manisha K., 2014. Phytochemical evaluation and pharmacological activity of syzygium aromaticum: a comprehensive review. Int. J. Pharm. Pharm. Sci., 6(8): 6772.

Moriya C., Hosoya T., Agawa S., Sugiyama Y., Kozone I., Shin-Ya K., Terahara N., Kumazawa S., 2015. New acylated anthocyanins from purple yam and their antioxidant activity. Biosci. Biotechnol. Biochem.,79(9):1484-1492.

Osagie AU., 1992. The yam tuber in storage. Nigeria: University of Benin, Post Harvest Research Unit.

Pervin R., Farah S, Billah MM.,.Didarul IKM., Elmezughi J., Shilpi JA., 2013. Antibacterial and cytotoxic activity of Meyna spinosa ROXB. stem. Turk. J. Pharm. Sci., 9(2): 225-230.

Rice-Evans C., Sampson J., Bramley PM., Holloway DE.. 1997. Why do we expect carotenoids to be antioxidants in vivo? Free Radical Res., 26: 381-398.

Saha S., Islam MK., Anisuzzman M., Hasan MM., Hossain F., Talukder C., 2012. Evaluation of antioxidant, analgesic and antidiarrhoeal activity of Phoenix paludosa Roxb. leaves. Int. J. Basic. Med. Sci. Pharm., 2: 46-52.

Saha S., Shilpi JA., Mondal H., Gofur R., Billah M., Nahar L., Satyajit DS., 2013. Bioactivity studies on Musa seminifera Lour. Phcog. Mag., 9(36): 315-322. 